\title{
Seasonal variations in vitamin D levels in HIV-infected patients
}

\author{
Sebastian Noe ${ }^{1}$, Silke Heldwein ${ }^{1}$, Rita Pascucci ${ }^{1}$, Celia Oldenbüttel ${ }^{1}$, Carmen Wiese ${ }^{1}$, Ariane von Krosigk ${ }^{1}$, \\ Eva Jägel-Guedes ${ }^{1}$, Hans Jäger ${ }^{1}$, Eva Wolf², Christoph D. Spinner ${ }^{1}$ \\ ${ }^{1}$ MVZ Karlsplatz, Munich, Germany \\ ${ }^{2}$ MUC Research, Munich, Germany
}

\begin{abstract}
Introduction: Human immunodeficiency virus (HIV)-infected patients treated with antiretroviral therapy (ART) are at high risk for vitamin D insufficiency, which is essentially caused by interference of medication with vitamin D metabolism. Under these conditions, the preservation of natural seasonal variability in vitamin D concentrations is not self-evident. Yet, for proper screening and interpretation of laboratory findings, knowledge about seasonality is essential. Aim of the study was to describe seasonal behavior in ART-treated HIV-infected patients in Central Europe.

Material and methods: It was a retrospective single-center study. Patients' medical records were screened for serum vitamin $D$ levels, $\beta$-crosslaps, and surrogate values of bone turnover.

Results: A total of 1011 datasets (625 patients) were evaluated. Overall, the median vitamin D level was $19.6 \mu \mathrm{g} / \mathrm{l}$. In 207 (16.4\%) datasets, patients were receiving oral cholecalciferol supplementation. Seasonal changes in serum vitamin D levels were reflected by minimum levels (median $13.5 \mu \mathrm{g} / \mathrm{l}$ ) in March and maximum levels (median $23.7 \mu \mathrm{g} / \mathrm{l}$ ) in July $(p<0.001)$. In contrast, serum calcium levels were lowest in September and October $(2.23 \mathrm{mmol} / \mathrm{l})$ and highest in May $(2.32 \mathrm{mmol} / \mathrm{l})$.

Conclusions: Significant variation in seasonal serum vitamin D levels was found in an unselected population of HIV-infected patients. This finding is in line with results from HIV-negative populations. Accordingly, the time point of vitamin D testing might be crucial for appropriate diagnosis of hypovitaminosis. We recommend vitamin D testing between December and May to provide the highest sensitivity. As serum calcium levels did not demonstrate the same pattern, the meaning of this finding is unclear and warrants further investigation.
\end{abstract}

HIV AIDS Rev 2017; 16: 50-53

DOI: https://doi.org/10.5114/hivar.2017.65397

Key words: vitamin $\mathrm{D}, \beta$-crosslaps, bone turnover, seasonal changes, HIV.

\section{Introduction}

The Endocrine Society (ES) guidelines on vitamin D are probably the most cited and respected recommendations on this topic [1]. Interesting for human immunodeficiency virus (HIV) caretakers is that they accommodate the fact of HIV-infected patients having a higher prevalence of 25-OH-cholecalciferol (vitamin D) insufficiency than matched HIV-negative controls [2]. But it also implies an interesting detail: more than HIV infection itself, the effect of antiretroviral therapy (ART) on vitamin D metabolism is a risk factor for vitamin $\mathrm{D}$ deficiency and insufficiency. Therefore, only HIV-infected patients on ART are consid-

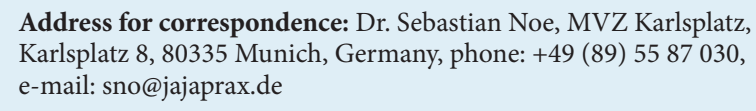

Article history:

Received: 13.09.2016

Received in revised form: 07.11.2016

Accepted: 08.11.2016

Available online: 24.01 .2017
International Journal of HIV-Related Problems

HIV \& AIDS

R e v i e w 
Table 1. Demographic characteristics of patients without cholecalciferol supplementation. Data are shown as absolute (\%) or median $(95 \% \mathrm{Cl})$

\begin{tabular}{|c|c|c|c|c|c|c|c|}
\hline \multirow{2}{*}{ Factor } & \multicolumn{2}{|c|}{ All } & \multicolumn{2}{|c|}{ Non-African population } & \multicolumn{2}{|c|}{ African population } & \multirow[b]{2}{*}{$p$} \\
\hline & $N$ & (\%) & $n$ & (\%) & $n$ & $(\%)$ & \\
\hline Male sex & 448 & 81.3 & 422 & 86.3 & 26 & 41.9 & \\
\hline Age & \multicolumn{2}{|c|}{47.0} & \multicolumn{2}{|c|}{48.0} & \multicolumn{2}{|c|}{38.5} & \\
\hline Patients & \multicolumn{2}{|c|}{551} & \multicolumn{2}{|c|}{489} & \multicolumn{2}{|c|}{62} & \\
\hline Datasets & \multicolumn{2}{|c|}{804} & \multicolumn{2}{|c|}{714} & \multicolumn{2}{|c|}{90} & \\
\hline Datasets per patient & \multicolumn{2}{|c|}{1.5} & \multicolumn{2}{|c|}{1.5} & \multicolumn{2}{|c|}{1.5} & \\
\hline Serum vitamin $D$, mean levels $[\mu \mathrm{g} / \mathrm{l}]$ & \multicolumn{2}{|c|}{$17.4(16.5-18.4)$} & \multicolumn{2}{|c|}{$18.6(17.5-19.4)$} & \multicolumn{2}{|c|}{$11.0(9.4-11.8)$} & $<0.001$ \\
\hline$\beta$-crosslaps, mean levels [ng/ml] & \multicolumn{2}{|c|}{$0.33(0.31-0.34)$} & \multicolumn{2}{|c|}{$0.33(0.32-0.35)$} & \multicolumn{2}{|c|}{$0.30(0.27-0.35)$} & 0.132 \\
\hline $\begin{array}{l}\text { Serum alkaline phosphatase, mean } \\
\text { levels [U/I] }\end{array}$ & \multicolumn{2}{|c|}{$83.0(81.0-85.0)$} & \multicolumn{2}{|c|}{$83.0(81.0-85.0)$} & \multicolumn{2}{|c|}{$84.5(77.0-89.0)$} & 0.800 \\
\hline Serum calcium, mean levels [mmol/l] & \multicolumn{2}{|c|}{$2.27(2.27-2.28)$} & \multicolumn{2}{|c|}{$2.28(2.27-2.29)$} & \multicolumn{2}{|c|}{$2.26(2.23-2.28)$} & 0.100 \\
\hline Serum phosphate, mean levels [mg/dl] & \multicolumn{2}{|c|}{$3.1(3.1-3.2)$} & \multicolumn{2}{|c|}{$3.1(3.0-3.1)$} & \multicolumn{2}{|c|}{$3.4(3.3-3.5)$} & $<0.001$ \\
\hline Serum creatinine, mean levels [mg/dl] & \multicolumn{2}{|c|}{$1.00(0.90-1.10)$} & \multicolumn{2}{|c|}{$1.00(0.90-1.10)$} & \multicolumn{2}{|c|}{$0.90(0.80-1.00)$} & $<0.001$ \\
\hline
\end{tabular}

ered at particular risk and screening is recommended for this subset of HIV-infected patients [1].

In a general population, daily sunlight exposure influences vitamin $\mathrm{D}$ serum concentrations, leading to strong seasonal intra- and inter-individual variability $[3,4]$. It is not self-evident, though, that these results can be transferred to HIV-infected subjects: for patients on anticonvulsant drugs (which are considered to interfere similarly to ART [1]) and patients with hyperparathyroidism (which was found to occur secondary to ART with tenofovir disoproxil fumarate $[5,6])$ a loss of seasonality has been described $[7,8]$. Although a seasonal difference has been hinted at in some small or highly selective HIV-infected populations [9-12], detailed information is sparse. Yet, knowledge about seasonality is essential for interpretation of laboratory results of vitamin D concentrations.

In the current observational study, we aimed to investigate changes in serum vitamin D levels and the course of markers of bone turnover throughout the year in HIVinfected patients in a large central European cohort.

\section{Material and methods}

All data were collected from medical records of HIV patients from a single HIV specialized outpatient center in Munich, Germany, between October 2014 and February 2016. Demographic data, including date of birth, sex, and ethnicity (African or non-African), cholecalciferol supplement status at the time of serum vitamin D measurement, co-medication, and laboratory parameters (vitamin $\mathrm{D}, \beta$-crosslaps, alkaline phosphatase $[\mathrm{AP}]$, serum creatinine, serum calcium, and serum phosphate) were collected. Only patients with values for both vitamin $\mathrm{D}$ and $\beta$-crosslaps were considered for analysis. Vitamin D insufficiency $(<30 \mu \mathrm{g} / \mathrm{l})$ and deficiency $(<20 \mu \mathrm{g} / \mathrm{l})$ were defined as per the Endocrine Society [1].
Unless otherwise declared, data are reported as medians with the corresponding 95\% confidence intervals (CI). Statistical analysis was performed using STATA SE 13.1 software (Stata, Texas, USA). Comparison for differences in two distinct groups was performed using the Mann-Whitney test. Comparison for differences in more than two groups was performed using the Kruskal-Wallis test. $P<0.05$ was considered statistically significant.

\section{Results}

A total of 1011 datasets from 623 patients were included, of which $505(81.1 \%)$ were men. Mean age was 47 years (range: 24-85), and 67 patients (10.8\%) were of African ethnicity. Median serum vitamin D level was $19.6 \mu \mathrm{g} / \mathrm{l}$ (95\% CI: 18.8-20.6). In 216 (21.4\%) datasets, vitamin D levels were $\geq 30 \mu \mathrm{g} / \mathrm{l}$; in 281 datasets (27.8\%), levels were 20.0-29.9 $\mu \mathrm{g} / \mathrm{l}$; in 191 (18.9\%) datasets, levels were $<10 \mu \mathrm{g} / \mathrm{l}$; and in 11 datasets (1.9\%), levels were $<4 \mu \mathrm{g} / \mathrm{l}$. In 207 datasets (20.5\%), patients were receiving cholecalciferol supplementation (Table 1).

To avoid bias by race, only non-African subjects of the entire study population were considered for detailed analysis of seasonal alterations in vitamin D levels and markers of bone turnover, as statistically significant differences were found between the ethnicity groups (Table 1).

\section{Non-African subpopulation without cholecalciferol supplementation}

This analyzed subset consisted of 714 datasets from 489 patients. In 598 datasets (83.8\%) and 435 patients (89.0\%), serum vitamin D levels $<30 \mu \mathrm{g} / \mathrm{l}$ were detected, consistent with vitamin D insufficiency. In 398 datasets (55.7\%) and 311 patients (63.6\%), vitamin D levels $<20 \mu \mathrm{g} / \mathrm{l}$ were found, consistent with vitamin D deficiency. 
Median vitamin D level in this group was $18.6 \mu \mathrm{g} / \mathrm{l}$. Vitamin D levels showed clear seasonal variation $(p<0.001)$, with the lowest median level occurring in March (12.1 $\mu \mathrm{g} / \mathrm{l})$, while the highest median level occurred in September (24.4 $\mu \mathrm{g} / \mathrm{l})$ (Figure 1). Median vitamin D levels differed from the lowest vitamin D levels in March $(13.8 \mu \mathrm{g} / \mathrm{l})$ as follows: January $\Delta+5.5 \mu \mathrm{g} / \mathrm{l}(p=0.001)$, February $\Delta+3.0 \mu \mathrm{g} / \mathrm{l}$ $(p=0.163)$, April $\Delta+2.6 \mu \mathrm{g} / \mathrm{l}(p=0.158)$, May $\Delta+5.4 \mu \mathrm{g} / \mathrm{l}$ $(p=0.136)$, June $\Delta+9.5 \mu \mathrm{g} / \mathrm{l}(p<0.001)$, July $\Delta+9.7 \mu \mathrm{g} / \mathrm{l}$ $(p<0.001)$, August $\Delta+9.3 \mu \mathrm{g} / \mathrm{l}(p<0.001)$, September $\Delta+12.3 \mu \mathrm{g} / \mathrm{l}(p<0.001)$, October $\Delta+7.0 \mu \mathrm{g} / \mathrm{l}(p<0.001)$, November $\Delta+4.2 \mu \mathrm{g} / \mathrm{l}(p=0.025)$, and December $\Delta+3.0 \mu \mathrm{g} / \mathrm{l}$ ( $p=0.207)$.

A polynomial trend line for the course of monthly mean vitamin $\mathrm{D}$ values on a population base throughout the year resulted in a sinusoidal line, with a maximum vitamin $\mathrm{D}$ level of $23.8 \mu \mathrm{g} / \mathrm{l}$ and a minimum of $13.1 \mu \mathrm{g} / \mathrm{l}$, therefore oscillating with an amplitude $(\varphi)$ of $5.35 \mu \mathrm{g} / \mathrm{l}$ on a baseline (b) of $18.5 \mu \mathrm{g} / \mathrm{l}$ with a period of about 10 months. The course of the median values could therefore be approximated by a modified sinus function, with ' $m$ ' being the month of testing (January $=1$ to October $=10$, November $=1$, December $=2$ ):

$$
y(m)=\mathrm{b}+\varphi \times(-\sin (2 \times \pi) / 10 \times(m-1))
$$

Median calcium level was $2.28 \mathrm{mmol} / \mathrm{l}$ (2.27-2.29). There was a significant change in calcium levels throughout the months, with the lowest levels occurring in September and October $(2.23 \mathrm{mmol} / \mathrm{l})$ and the highest levels occurring in May $(2.32 \mathrm{mmol} / \mathrm{l})(p<0.001)$. There was no significant seasonal variation of $\beta$-crosslaps $(p=0.333), \mathrm{AP}(p=0.059)$, or phosphate $(p=0.063)$.

\section{Discussion}

While there is a consensus on screening HIV-infected patients for vitamin D deficiency [1], details about the influence of ART on seasonality of vitamin D concentrations have not been reported so far. Yet, this knowledge is essential for proper interpretation of the results while several considerations give rise to doubt about the transferability of data from general populations.

The present study demonstrates significant seasonal changes in vitamin D levels in a large population of HIVinfected, mainly Caucasian patients from Central Europe treated with a wide variety of antiretroviral drugs. The changes seemed to be well approximated by a modified sinusoidal curve. Since this function also reflects the time of exposure to sunlight and intensity, the term $\varphi$ (5.35 in our study) might be a function of individual factors. However, as vitamin D levels vary with latitude in Caucasians [13], $\varphi$ may also be a function of latitude (Munich, Germany: 48.14'). The difference between the lowest and highest median vitamin D levels was as high as $12.3 \mu \mathrm{g} / \mathrm{l}$ - an enormous magnitude given a continuous threshold of only $30 \mu \mathrm{g} / \mathrm{l}$.

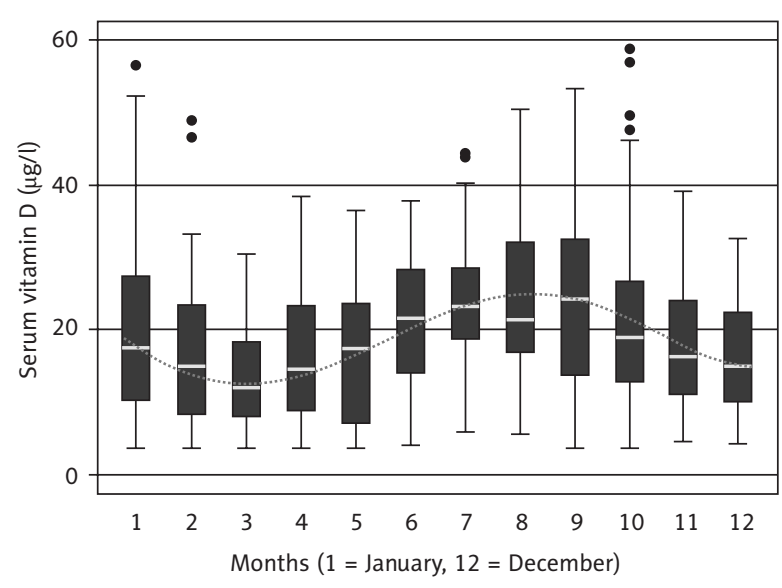

Figure 1. Monthly changes of serum vitamin D levels. Monthly distribution of serum vitamin $D$ levels showing seasonal changes in non-African patients not taking cholecalciferol $(p<0.001)$. The dotted line shows a polynomial trend line

Time of testing is not explicitly stated in most relevant guidelines and recommendations, implying that every patient with concentrations below the threshold at any time will be considered insufficient or deficient. In other words, a subject's lowest vitamin D level will classify the subject's vitamin D status. To provide high sensitivity for screening for vitamin $\mathrm{D}$ insufficiency in a high-risk population we should therefore try to screen during the time of the lowest expected vitamin D levels. The lowest concentrations of vitamin D levels in our study population were found in March. However, with the exception of January, vitamin D levels from December to May did not differ significantly from those in March. We hypothesize that the unexpected high vitamin $\mathrm{D}$ levels in January were caused by inclusion of data from January 2016, which had a preceding mild and sunny winter season, compared to prior years (about 307 hours of sunlight from October to December 2015 compared to about 180 hours of sunlight during the same time in 2014) $[14,15]$.

Based on the present findings, screening with the highest sensitivity for vitamin $D$ insufficiency in non-African HIV-infected patients in Central Europe would be between December and May.

Interestingly, of all other analyzed parameters, only calcium showed seasonal variation. This raises the question whether seasonal changes in vitamin $\mathrm{D}$ levels are of any importance concerning bone health, particularly the development of osteoporosis.

A possible limitation of our study is a potential selected population bias, which would suggest that the values obtained throughout the year are independent samples. However, since all samples were obtained from routine analysis based on an alphabetic system, the chance of selection bias was minimized; accordingly, inter-individual changes may be representative of individual changes. 


\section{Conclusions}

In conclusion, we demonstrated significant month-tomonth changes in serum vitamin D levels in HIV-infected patients. As vitamin $\mathrm{D}$ supplementation and accurate testing of vitamin $\mathrm{D}$ levels may help to prevent bone disease in HIV-infected patients, we recommend testing between December and May, when the lowest serum vitamin D levels are expected, providing the highest sensitivity to vitamin D insufficiency and deficiency. Of markers of bone turnover, only serum calcium levels showed seasonal variation. This raises questions regarding whether seasonal serum vitamin $\mathrm{D}$ variability is related to bone health in HIV-infected patients.

\section{Ethics approval}

Measurement of serum vitamin D levels and bone turnover parameters took place within clinical routine practice. Therefore, under German regulations, this study did not require formal ethical approval.

\section{Conflict of interest}

The author's declared no potential conflicts of interest with respect to the research, authorship, and/or publication of this article.

\section{References}

1. Holick MF, Binkley NC, Bischoff-Ferrari HA, et al. Evaluation, treatment, and prevention of vitamin D deficiency: an Endocrine Society clinical practice guideline. J Clin Endocrinol Metab 2011; 96: 1911-1930.

2. Pinzone MR, Di Rosa M, Malaguarnera M, et al. Vitamin D deficiency in HIV infection: an underestimated and undertreated epidemic. Eur Rev Med Pharmacol Sci 2013; 17: 1218-1232.

3. Kopec A, Solarz K, Majda F, et al. An evaluation of the levels of vitamin $\mathrm{d}$ and bone turnover markers after the summer and winter periods in polish professional soccer players. J Hum Kinet 2013; 38: 135-140.

4. Pludowski P, Grant WB, Bhattoa HP, et al. Vitamin D status in central Europe. Int J Endocrinol 2014; 2014: 589587.

5. Patricio JA Jr, Lopes PF, Medeiros T, et al. Tenofovir monotherapy for hepatitis B after 1 year does not produce renal dysfunction, but is associated with hyperparathyroidism not related to vitamin D. Eur J Gastroenterol Hepatol 2016; 28: 64-69.

6. Masiá M, Padilla S, Robledano C, et al. Early changes in parathyroid hormone concentrations in HIV-infected patients initiating antiretroviral therapy with tenofovir. AIDS Res Hum Retroviruses 2012; 28: 242-246.

7. Nettekoven S, Strohle A, Trunz B, et al. Effects of antiepileptic drug therapy on vitamin D status and biochemical markers of bone turnover in children with epilepsy. Eur J Pediatr 2008; 167: 1369-1377.

8. Cong E, Walker MD, Kepley A, et al. Seasonal Variability in Vitamin D Levels No Longer Detectable in Primary Hyperparathyroidism. J Clin Endocrinol Metab 2015; 100: 3452-3459.

9. Mueller NJ, Fux CA, Ledergerber B, et al. High prevalence of severe vitamin $\mathrm{D}$ deficiency in combined antiretroviral therapy-naive and successfully treated Swiss HIV patients. AIDS 2010; 24: 1127-1134

10. Viard JP, Souberbielle JC, Kirk O, et al. Vitamin D and clinical disease progression in HIV infection: results from the EuroSIDA study. AIDS 2011; 25: 1305-1315.
11. Cervero M, Agud JL, Torres R, et al. Higher vitamin D levels in HIV-infected out-patients on treatment with boosted protease inhibitor monotherapy. HIV Med 2013; 14: 556-562.

12. Martineau AR, Nhamoyebonde S, Oni T, et al. Reciprocal seasonal variation in vitamin $\mathrm{D}$ status and tuberculosis notifications in Cape Town, South Africa. Proc Natl Acad Sci U S A 2011; 108: 1901319017.

13. Hagenau T, Vest R, Gissel TN, et al. Global vitamin D levels in relation to age, gender, skin pigmentation and latitude: an ecologic meta-regression analysis. Osteoporosis Int 2009, 20: 133-140.

14. Pressemitteilung - Wärmster Dezember seit 1881 folgt auf Rekord-November; available at: http://www.dwd.de/DE/presse/pressemitteilungen/DE/2015/20151230_deutschlandwetter_dezember. pdf?_blob=publicationFile\&v=2

15. Available at: http://www.wetterkontor.de/de/wetter/deutschland/ monatswerte-station.asp 